Jurnal Kesehatan Karya Husada, Vol 9 No 1 Tahun 2021

PISSN 2337649X/EISSN 2655-8874

Woro Ispandiyah, Parmadi Sigit Purnomo, Muhammad Irfan Fahrudin “Jarak dan Posisi Duduk Tidak Memiliki Hubungan dengan Efektivitas Belajar Mahasiswa STIKes Surya Global Yoggyakrya (hal 49-55)

Received

10 Desember 2020

Revisied

20 Februari 2021

Acceptep

16 Juni 2021

\title{
JARAK DAN POSISI DUDUK TIDAK MEMILIKI HUBUNGAN DENGAN EFEKTIFITAS BELAJAR MAHASISWA STIKES SURYA GLOBAL YOGYAKARTA
}

\author{
Woro Ispandiyah $^{1)}$, Parmadi Sigit Purnomo' ${ }^{2}$, Muhamad Irfan Fahrudin ${ }^{3)}$ \\ ${ }^{123}$ STIKES Surya Global Yogyakarta \\ ${ }^{1}$ Email : woroispandiyah87@gmail.com
}

\begin{abstract}
ABSTRAK
Latar Belakang: Lingkungan belajar merupakan salah satu aspek yang mempengaruhi proses pembelajaran mahasiswa. Jarak dan Posisi tempat duduk merupakan variabel yang terkait dengan lingkungan belajar mahasiswa, Posisi yang ergonomi dapat membantu kenyamanan selama proses pembelajaran. Penelitian ini ingin mengetahui hubungan posisi dan jarak tempat duduk terhadap efektiftas belajar mahasiswa STIKes Surya Global Yogyakarta.Desain penelitian kuantitatif eksperimen dengan rancangan penelitian desriptif kuantitatif dan pendekatan cross sectional. Jumlah sample yang diambil sebanyak 44 respoden dari populasi 175 orang dengan teknik purposive sampling dimana mengambil responden yang saat itu sedang melakukan perkuliahan. Adapun penelitian ini digunakan alat ukur kuesioner efektfitas belajar dan pengukuran jarak dan posisi tempat duduk. Peneltian ini metode analisis data dengan Chi-Square.Berdasar hasil uji analisis didapat bahwa tidak ada pengaruh yang bermakna antara jarak terhadap efektivitas belajar mahasiswa (P Sig= 0,783) dan tidak ada pengaruh juga antara posisi tempat duduk terhadap efektivitas belajar mahasiswa (P Sig $=0,361$ ). Tidak ada pengaruh yang signifikan antara jarak dan posisi tempat duduk terhadap efektivitas belajar mahasiswa di Stikes Surya Global Yogyakarta
\end{abstract}

Kata Kunci: Ergonomi, Efektivitas belajar, Jarak, Posisi Duduk

\section{DISTANCE AND SITTING POSITION HAS NO RELATIONSHIP WITH THE LEARNING EFFECTIVENESS OF YOGYAKARTA GLOBAL SURYA STIKES STUDENTS}

Background: The learning environment is one aspect that influences the student learning process. Distance and seat position are variables related to the student learning. An ergonomic position can help comfort during the learning process. This study wanted to determine the relationship between seat position and distance to the learning effectiveness of STIKes Surya Global Yogyakarta students.Experimental quantitative research design with quantitative descriptive research design and cross sectional approach. The number of samples taken was 44 respondents from a population of 175 people with a purposive sampling technique which respondents who were currently conducting lectures. The research used a learning effectiveness questionnaire measuring instrument and measuring the distance and position of the seat. This research is a data analysis method with Chi-Square.Based on the results of the analysis test, it was found that there was no significant effect between distance on student learning effectiveness (P Sig $=0,783$ ) and there is also no influence between seating position on student learning effectiveness (P Sig = 0,361).There is no significant effect between distance and seat position on the effectiveness of student learning at Stikes Surya Global Yogyakarta 2020.

Keywords: Ergonomics, learning effectiveness, distance, seating position 
Jurnal Kesehatan Karya Husada, Vol 9 No 1 Tahun 2021

PISSN 2337649X/EISSN 2655-8874

Woro Ispandiyah, Parmadi Sigit Purnomo, Muhammad Irfan Fahrudin "Jarak dan Posisi Duduk Tidak Memiliki Hubungan dengan Efektivitas Belajar Mahasiswa STIKes Surya Global Yoggyakrya (hal 49-55)

\section{PENDAHULUAN}

Proses belajar mengajar merupakan suatu sistem yang komponennya saling berinteraksi sebagai satu kesatuan. Komponen sistem tersebut adalah task, organisasi dan lingkungan. Kombinasi antara tugas (task), organisasi (organization) dan lingkungan (environment) merupakan kondisi kerja yang harus diterima dalam proses belajar mengajar. Apabila ruangan berfungsi tidak hanya sebagai tempat belajar namun untuk kegiatan organisasi maka kondisi belajar menjadi tidak sehat, tidak aman, tidak nyaman dan tidak efektif (Adnyani, 2015).

Fasilitas pembelajaran yang baik harus memiliki sarana fisik yang berupa peralatan dan perlengkapan belajar di ruang belajar dan sarana non fisik berupa kurikulum, manajemen, metode pembelajaran, evaluasi dan mutu pembelajaran. Namun ruang kelas yang ergonomis merupakan faktor penting dalam menciptakan proses belajar mengajar agar sesuai dengan tujuan yang diharapkan. Suatu ruang kelas biasanya terdiri dari sarana fisik. Sarana fisik terdiri dari kursi kuliah, papan tulis, AC, bahkan ruang kuliah yang sudah maju dilengkapi dengan proyektor dan layar display untuk meningkatkan proses transfer ilmu dan pengetahuan dari dosen kepada para mahasiswanya lebih efektif (Sukanta \& Winarko, 2012)

$$
\text { Menurut Partin }
$$

mengemukakan bahwa posisi tempat duduk peserta didik memang mempunyai pengaruh terhadap prestasi di kelas. Dimana peserta didik yang duduk dibangku depan mau tidak mau harus memperhatikan pendidik yang sedang mengajar, sehingga secara tidak langsung peserta didik tersebut akan mudah menyerap materi. Berbeda dengan peserta didik yang duduk dibelakang, mereka memiliki kesempatan lebih banyak untuk tidak memperhatikan pendidik dalam proses pembelajaran.

Menurut Adnyani (2015) Seorang dosen membutuhkan media agar apa yang disampaikan dapat diserap, dimengerti, dan dipahami oleh mahasiswa dengan lebih mudah dan lebih cepat. Untuk dapat mempermudah proses tersebut, maka dosen membutuhkan media yang tepat dalam perkuliahan. Salah satu media untuk menyajikan materi perkuliahan yang paling efektif adalah media LCD (Liquid Crystal Display) proyektor.

Pemaparan diatas dapat disimpulkan bahwa mahasiswa dapat lebih mudah menangkap atau memahami pelajaran dengan menggunakan teknologi LCD proyektor yang ditata sedemikian rupa untuk mempermudah mahasiswa dalam melihat materi yang diberikan oleh dosen, desain LCD proyektor yang tidak ergonomis dapat mengganggu pengelihatan mahasiswa ketika akan belajar, sehingga menyebabkan kelelahan saat proses belajar mengajar dan tidak dapat menangkap pelajaran dengan efektif dan efisien.

Berdasarkan wawancara yang peneliti dengan 10 responden mahasiswa,ditemukan hasil bahwa semua responden mahasiswa terganggu dengan jarak tempat duduk terhadap screen proyektor yang terlalu dekat, sehingga banyak dari mahasiswa memilih untuk duduk kursi paling belakang karena menurut mereka duduk pada bangku/kursi yang paling belakang akan 
Jurnal Kesehatan Karya Husada, Vol 9 No 1 Tahun 2021

PISSN 2337649X/EISSN 2655-8874

Woro lspandiyah, Parmadi Sigit Purnomo, Muhammad Irfan Fahrudin "Jarak dan Posisi Duduk Tidak Memiliki

Hubungan dengan Efektivitas Belajar Mahasiswa STIKes Surya Global Yoggyakrya (hal 49-55)

membuat meraka merasa nyaman dan lebih efektif untuk menerima pelajaran, karena posisi kepala mereka akan sejajar dengan screen proyektor sehingga tidak menimbulkan kelelahan pada bagian leher. Dari masalah tersebut maka dilakukan penelitian "Analisis Jarak dan Posisi Tempat Duduk Terhadap Efektifitas Belajar Mahasiswa di STIKES Surya Global Yogyakarta"

\section{METODE PENELITIAN}

Metode yang digunakan dalam penelitian adalah metode deskrptif kuantitatif eksperime dan pendekatan cross sectional. Populasi dalam penelitian adalah seluruh mahasiswa kesehatan masyarakat semester III Angkatan 2018 di kampus STIKes Surya Global Yogyakarta yang berjumlah 175 mahasiswa. Adapun sampel dalam penelitian ini adalah dengan purposive sampling pengambilan sampel lakukan dengan cara menetapkan sejumlah sample didapatkan 44 mahasiswa yang saat itu berada di kampus dan sedang belajar di kelas.

Teknik pengambilan data dengan menggunakan kuesioner efektivitas belajar mahasiswa dan dilakukan pengukuran langsung terhadap jarak dan posisi tempat duduk dengan menggunakan meteran.

Analisis data yang digunakan adalah uji univariat dan uji bivariat dengan chi square test yang dimana dengan membandingkan adanya pengaruh antara masing-masing variabel.

\section{HASIL DAN PEMBAHASAN}

1. Analisis Univariat
Responden dalam penelitian ini dapat dikategorikan dalam beberapa karakteristik yaitu berdasarkan jenis kelamin dan umur.

\begin{tabular}{lcc}
\hline Karakterstik & Frekuensi & $\%$ \\
\hline Jeniskelamin & & \\
Perempuan & 44 & 100,0 \\
Laki-laki & 0 & 0 \\
\hline Umur & & \\
19 Tahun & 5 & 11,4 \\
20 Tahun & 36 & 81,8 \\
21 Tahun & 3 & 6,8 \\
\hline Kelas & & \\
B KM & 23 & 52.3 \\
D KM & 21 & 47,7 \\
\hline Total & $\mathbf{4 4}$ & $\mathbf{1 0 0 , 0}$ \\
\hline
\end{tabular}

Pengukuran jarak dilakukan dengan mengukur jarak kursi yang terdapat didalam kelas terhadap layar proyektor mulai dari yang terdekat sampai yang terjauh dengan menggunakan meteran, kemudian dikelompokkan berdasarkan standar jarak yang telah ditentukan yaitu jarak yang ergonomi dan jarak yang tidak ergonomi. Berikut ini merupakan gambaran distribusi frekuensi dari variabel jarak di ruang 5 Kampus Stikes Surya Global Yogyakarta yang diperoleh dari hasil pengukuran.

\section{Distribusi Frekuensi Berdasarkan Variabel Jarak di Stikes Surya Global Yogyakarta Tahun 2020

$\mathrm{N}$ Kateg Frekue Persen \\ o ori nsi tase}

$(\%)$ 
Jurnal Kesehatan Karya Husada, No 9 Vol 1 Tahun 2021

PISSN 2337649X/EISSN 2655-8874

Woro lspandiyah, Parmadi Sigit Purnomo, Muhammad Irfan Fahrudin "Jarak dan Posisi Duduk Tidak Memiliki Hubungan dengan Efektivitas Belajar Mahasiswa STIKes Surya Global Yoggyakrya (hal 49-55)

\begin{tabular}{llll}
\hline 1 & Ergonomi & 36 & 81,8 \\
2 & TidakErg & 8 & 18,2 \\
& onomi & & \\
& & &
\end{tabular}

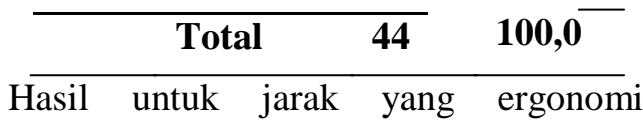

sebanyak 36 dengan persentase sebesar $(81,8$

\%) dan jarak yang tidak ergonomi sebanyak 8 dengan frekuensi sebesar (18,2\%). Dari hasil diatas dapat diketahui bahwa jarak bangku dengan kategori ergonomi yang paling banyak yaitu berjumlah 36 dengan persentasi sebesar $(81,8 \%)$.

Pengukuran posisi tempat duduk dilakukan dengan melihat deretan bangku yang terdapat di ruang kelas secara horizontal, terdapat 4 derat bangku kebelakang, kemudian dikelompokkan berdasarkan kategori yang telah ditentukan yaitu paling depan sangat baik, kedua baik, ketiga atau cenderung dibelakang sedang dan paling belakang kurang. Berikut ini merupakan gambaran distribusi frekuensi dari variabel posisi tempat duduk di ruang 5 kampus Stikes Surya Global Yogyakarta.

\section{Distribusi Frekuensi Berdasarkan} Variabel Posisi Tempat Duduk di Stikes Surya Global Yogyakarta Tahun 2020

\begin{tabular}{|c|c|c|c|}
\hline No & Kategori & $\begin{array}{l}\text { Frekuen } \\
\text { si } \\
\end{array}$ & $\begin{array}{l}\text { Persentas } \\
\mathrm{e}(\%)\end{array}$ \\
\hline 1 & SangatBaik & 11 & 25,0 \\
\hline 2 & Baik & 11 & 25,0 \\
\hline 3 & Cukup & 11 & 25,0 \\
\hline 4 & Kurang & 11 & 25,0 \\
\hline & Total & 44 & 100,0 \\
\hline
\end{tabular}

Hasil dari kategori posisi tempat duduk sangat baik sebanyak 11 dengan persentasi sebesar $(25,0$ $\%)$, sedangkan kategori baik sebanyak 11 dengan persentasi sebesar $(25,0 \%)$, sedangkan kategori sedang sebanyak 11 dengan persentasi sebesar $(25,0 \%)$, sedangkan kategori kurang sebanyak 11 dengan persentasi sebesar $(25,0 \%)$.

Pengukuran variabel efektivitas belajar menggunakan skor berdasarkan penilaian responden terhadap kuesioner yang kemudian dikelompokkan berdasarkan kategori efektivitas belajar baik, efektivitas belajar cukup, dan efektivitas belajar kurang. Berikut ini merupakan gambaran distribusi frekuensi dari variabel efektivitas belajar mahasiswa di Stikes Surya Global Yogyakarta yang diperoleh dari responden penelitian.

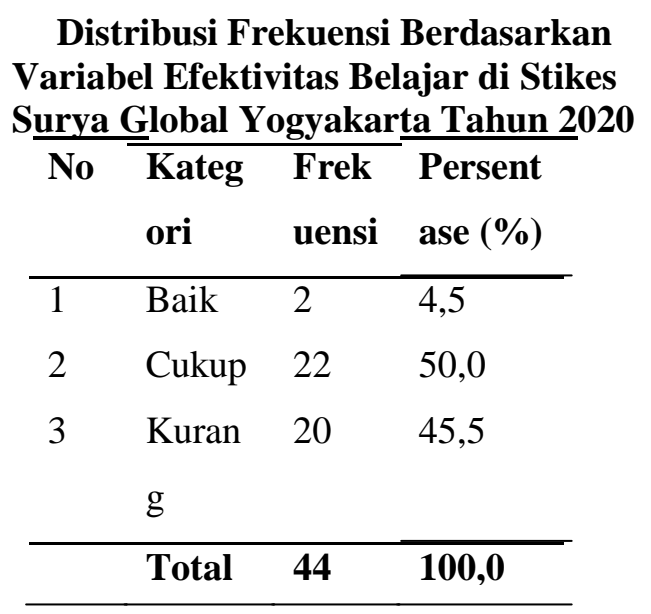

Diketahui bahwa distribusi frekuensi variabel efektivitas belajar mahasiswa didapatkan hasil untuk kategori efektivitas belajar baik sebanyak 2 responden dengan persentasi sebesar $(4,5 \%)$, sedangkan untuk kategoriefektivitas belajar cukup sebanyak 22 responden dengan persentasi sebesar $(50,0 \%)$, dan sedangkan untuk 
Jurnal Kesehatan Karya Husada, No 9 Vol 1 Tahun 2021

PISSN 2337649X/EISSN 2655-8874

Woro lspandiyah, Parmadi Sigit Purnomo, Muhammad Irfan Fahrudin "Jarak dan Posisi Duduk Tidak Memiliki Hubungan dengan Efektivitas Belajar Mahasiswa STIKes Surya Global Yoggyakrya (hal 49-55)

kategori efektivitas belajar kurang sebanyak 20 responden dengan persentasi sebesar $(45,5 \%)$.

1. Analisis bivariat

a. Pengaruh jarak terhadap efektivitas belajar mahasiswa

Dari Analisis didapatkan hasil bahwa sebanyak 4 responden dengan persentase sebesar $(50.0 \%)$ memiliki efektivitas belajar kurang dengan jarak tidak ergonomi, 4 responden dengan persentase sebesar $(50.0 \%)$ memiliki efektivitas belajar cukup dengan jarak tidak ergonomi, 0 responden memiliki efektivitas belajar baik dengan jarak tidak ergonomi, 16 responden dengan persentasi sebesar $(44,4 \%)$ memiliki efektivitas belajar kurang dengan jarak ergonomi, 18 responden dengan persentasi sebesar $(50,0 \%)$ memiliki efektivitas belajar cukup dengan jarak ergonomi, 2 responden dengan persentasi sebesar $(5,0 \%)$ memiliki efektivitas belajar baik dengan jarak ergonomi.

Berdasarkan hasil analisis uji Chisquare dengan menggunakan SPSS menunjukkan bahwa tidak adanya pengaruh yang signifikan atau positif antara jarak terhadap efektivitas belajar mahasiswa, dari hasil uji statistik diperoleh P Sigsebesar 0,783 hal ini menunjukkan bahwa P Sig > dari Alpha 0,05. Maka Ha ditolak dan Ho diterima sehingga dapat diartikan bahwa tidak adanya pengaruh antara jarak terhadap efektivitas belajar mahasiswa.

Penelitian ini didukung oleh penelitian yang dilakukan oleh Muman \& Hadiansyah (2016) tentang analisis jarak dan sudut pandang posisi duduk pada ruang pekuliahan terhadap efektivitas belajar mahasiswa. Dimana hasil yang ditemukan dalam penelitian tersebut adalah sudut pandang tidak berpengaruh terhadap deret tapi berpengaruh terhadap baris. Semakin jauh tempat duduk maka semakin kecil sudut. Sudut pandang tidak berpengaruh terhadaplayar proyektor. Sehingga secara garis besar dapat disimpulkan bahwa jarak tidak berpengaruh pada efektivitas mahasiswa dalam proses belajar.

b. Pengaruh posisi tempat duduk terhadap efektivitas belajar mahasiswa

Dari Analisis didapatkan hasil bahwa sebanyak 6 responden dengan persentasi sebesar $(54,5 \%)$ memiliki efektivitas belajar kurang dengan posisi tempat duduk kurang, 5 responden dengan persentasi (45,5 \%) memiliki efektivitas belajar cukup dengan posisi tempat duduk kurang, 5 responden dengan persentasi sebesar $(45,5 \%)$ memiliki efektivitas belajar kurang dengan posisi tempat duduk cukup, 6 responden dengan persentasi $(54,5 \%)$ memiliki efektivitas belajar cukup dengan posisi tempat duduk cukup, 4 responden dengan persentasi $(36,4$ $\%)$ memiliki efektivitas belajar kurang dengan posisi tempat duduk baik, 5 responden dengan persentasi sebesar $(45,5 \%)$ memiliki efektivitas belajar cukup dengan posisi tempat duduk baik, 2 responden dengan persentasi sebesar $(18,2 \%)$ memiliki efektivitas belajar baik dengan posisi tempat duduk baik, 5 responden dengan persentasi sebesar $(45,5 \%)$ 
Jurnal Kesehatan Karya Husada, No 9 Vol 1 Tahun 2021

PISSN 2337649X/EISSN 2655-8874

Woro Ispandiyah, Parmadi Sigit Purnomo, Muhammad Irfan Fahrudin "Jarak dan Posisi Duduk Tidak Memiliki

Hubungan dengan Efektivitas Belajar Mahasiswa STIKes Surya Global Yoggyakrya (hal 49-55)

memiliki efektivitas belajar kurang dengan posisi tempat duduk sangat baik, 6 responden dengan persentasi sebesar $(54,5 \%)$ memiliki efektivitas belajar cukup dengan posisi tempat duduk sangat baik.

Berdasarkan hasil analisis uji Chisquare dengan menggunakan SPSS menunjukkan bahwa tidak adan=ya pengaruh yang signifikan atau positif antara posisi tempat duduk terhadap efektivitas belajar mahasiswa, dari hasil uji statistik diperoleh $\mathrm{P}$ Sigsebesar 0,361 hal ini menunjukkan bahwa P Sig > dari Alpha 0,05. Maka Ha ditolak dan Ho diterima sehingga dapat diartikan bahwa tidak adanya pengaruh antara posisi tempat duduk terhadap efektivitas belajar mahasiswa.

Penelitian ini didukung oleh penelitian yang dilakukan oleh Amelia et all (2017) tentang efektivitas formasi tempat duduk terhadap hasil belajar siswa. Dimana hasil yang ditemukan dalam penelitian tersebut adalah pada setiap aspek menunjukkan kelas eksperimen I memiliki N-gain dan peningkatan nilai tertinggi. Oleh karena itu, terdapat perbedaan efektivitas dari ketiga formasi tempat duduk yang diterapkan terhadap hasil belajar siswa. Penelitian ini didukung juga oleh penelitian yang dilakukan oleh Afifah (2017) tentang pengaruh tata ruang kelas terhadap motivasi belajar. Dimana hasil yang ditemukan dalam penelitian tersebut adalah uji-t satu sampel (One Sample T-Test) tersebut dapat disimpulkan bahwa signifikasi 0,000, karena signifikasi $<0,05$ maka Ho diterima dan $\mathrm{Ha}$ ditolak, artinya rata-rata motivasi belajar siswa kelas $6 \mathrm{Sd}$ ada perbedaan atau ada pengaruh

\section{SIMPULAN DAN SARAN}

\section{SIMPULAN}

Berdasarkan hasil penelitian dan analisis menunjukkan bahwa tidak adanya pengaruh jarak dan posisi tempat duduk terhadap efektivitas belajar mahasiswa di Stikes Surya Global Yogyakarta tahun 2020.

\section{SARAN}

1. Bagi STIKES Surya Global diharapkan bisa mempertahankan jarak dan posisi tempat duduk atau memvariasi tata ruang dalam belajar.

2. Bagi mahasiswa agar dapat memilih posisi tempat duduk yang nyaman agar dapat mempengaruhi semangat, niat, minat dan konsentrasi mahasiswa.

3. Bagi peneliti selanjutnya, peneliti menyarankan untuk dapat lebih mengembangkan variabel tentang pengaruh jarak dan posisi tempat duduk terhadap efektivitas belajar mahasiswa yang dipadukan dengan faktor-faktor eksternal maupun internal lainnya.

\section{DAFTAR PUSTAKA}

Adnyani, I.A. Sri. 2015. Layout Proyektor LCD Yang Ergonomis Pada Ruang Kuliah Jurusan Teknik Elektro Universitas Mataram; Studi Kasus Jurusan Teknik Elektro. Vol. 2, No 1:1-5, Februari 2015.

Afifah, Siti Nur. 2017. Pengaruh Tata Ruang Kelas Terhadap Motivasi 
Jurnal Kesehatan Karya Husada, No 9 Vol 1 Tahun 2021 PISSN 2337649X/EISSN 2655-8874

Woro lspandiyah, Parmadi Sigit Purnomo, Muhammad Irfan Fahrudin "Jarak dan Posisi Duduk Tidak Memiliki Hubungan dengan Efektivitas Belajar Mahasiswa STIKes Surya Global Yoggyakrya (hal 49-55)

Belajar. Pendidikan Agama Islam.

Universitas Darul Ulum

Afzan, Zarith et al. 2012. Mismatch

Between School Furniture And

Anthropometric Measures Among

Primary School Children In Mersing,

Johor. University Putra Malaysia,

Selangor:Malaysia.

Ahlstrom, V., \& Kudrick, B., Human

Factors Criteria for Display s: A

Human Factors Design Standard

Update of Chapter 5, Department of

Transportation, Uni Soviet, (2007).

Amelia, Clara., Achmad, Arwin., Rita,

Rini., Marpaung. 2017. Efektivitas

Formasi Tempat Duduk Terhadap

Hasil Belajar Siswa di Kelas VII.

Pendidikan Biologi FKIP Universitas

Lampung.

Aminah, P. F. 2013. Kajian Antropometri

dan Penataan Ruang Pada Ruang

Perkuliahan Fakultas Teknik

Universitas Negeri Semarang; Studi

Kasus Jurusan Teknik Sipil. Fakultas

Teknik Sipil Universitas Negeri

Semarang.

Kementrian Kesehatan RI, 2016.

Kesehatan dan Keselamatan Kerja.

Jakarta: http//www.kemkes.go.id.

Kurniawan, R., Hasri, L. K.,

Wuryaningtyas, P.D., Hartono, G.

2012. Perancangan Area Mengajar

pada Ruangan Kelas Kampus

Syahdan Binus University dengan

Pendekatan Analisis Aspek
Ergonomi. 2012. Available at: https:www.thesis.binus.ac.id. 